\title{
Shear Wave Velocity Prediction Using Seismic Attributes and Well Log Data
}

\author{
Raoof GHOLAMI ${ }^{1}$, Ali MORADZADEH ${ }^{1}$, Vamegh RASOULI ${ }^{2}$, \\ and Javid HANACHI ${ }^{3}$ \\ ${ }^{1}$ Department of Mining, Petroleum and Geophysics, \\ Shahrood University of Technology, Shahrood, Iran \\ e-mail: Raoof.Gholami@Gmail.com \\ ${ }^{2}$ Department of Petroleum Engineering, Curtin University, Perth, Australia \\ ${ }^{3}$ Petroleum Geology, Tehran, Iran
}

\begin{abstract}
Formation's properties can be estimated indirectly using joint analysis of compressional and shear wave velocities. Shear wave data is not usually acquired during well logging, which is most likely for cost saving purposes. Even if shear data is available, the logging programs provide only sparsely sampled one-dimensional measurements: this information is inadequate to estimate reservoir rock properties. Thus, if the shear wave data can be obtained using seismic methods, the results can be used across the field to estimate reservoir properties. The aim of this paper is to use seismic attributes for prediction of shear wave velocity in a field located in southern part of Iran. Independent component analysis (ICA) was used to select the most relevant attributes to shear velocity data. Considering the nonlinear relationship between seismic attributes and shear wave velocity, multi-layer feed forward neural network was used for prediction of shear wave velocity and promising results were presented.
\end{abstract}

Keywords: shear wave velocity, seismic attributes, regression analysis, independent component analysis, multi-layer feed forward neural network. 


\section{INTRODUCTION}

Compressional and shear wave velocities $\left(V_{p}\right.$ and $\left.V_{s}\right)$ are essential parameters for hydrocarbon reservoir evaluation including lithology indication, porosity calculation, identification of reservoir-fluids, estimation of permeability, fracture evaluation and geophysical/geomechanical studies (Singh et al. 2012). This indicates the importance of acquiring both compression and shear sonic data. These parameters are obtained directly from core analysis in laboratory or dipole sonic imager (DSI) tools run during well logging. The direct measurements using core samples in the lab cannot provide continued information about the interval of interest since few core samples are taken at few depths due to cost and technical difficulties associated with sampling. DSI tool is also an expensive logging tool which is not usually run during well logging. Attempts have been made to find alternative methods for shear wave velocity estimation. Many researchers have tried to predict $V_{s}$ from well log data (e.g., Castagna et al. 1993, Gassmann 1951, Greenberg and Castagna 1992, Eberhart-Phillips et al. 1989, Krief et al. 1990, Picket 1963, Rezaee and Applegate 1997). For example, Wantland (1964) assumed a Poisson's ratio for reservoir rocks and estimated shear wave velocities. However, the Poisson's ratio is changing in a wide range in practice; hence the accuracy of estimated shear sonic data is questionable (Carroll 1969). Another approach is to measure $V_{s}$ using pulse transmission techniques applied on core samples in laboratory (Birch 1960, Christensen 1974, Kern 1982, Burlini and Fountain 1993, Ji and Salisbury 1993, Watanabe et al. 2007). However, few lab data is available for $V_{s}$ measurements comparing to those of $V_{p}$ (Ji et al. 2002). This is due mainly to the difficulties of $V_{s}$ measurements at low pressures, as transmission of shear wave through the sample requires a firm contact between the transducers and the end surfaces of the specimen. Since variations of shear wave velocity are related to the rock type, mechanical properties and loading conditions, the laboratory measurements cannot ideally simulate downhole field conditions (e.g., state of in situ stresses and fluid content). In addition, the information obtained is not very reliable statistically since limited core samples are taken for mechanical lab experiments. Another approach is to use empirical correlations reported during last decades to estimate shear wave velocity from rock physical properties (Castagna et al. 1993, Brocher 2005, 2008, Ameen et al. 2009, Yasar and Erdogan 2004). However, these correlations have been developed based on data collected from a certain area or field so their applications for a different field should be exercised carefully. In addition to this, it should also be mentioned that these correlations are based on 1D data obtained from petrophysical logs run in a well, so is not a good representative of rock properties in the entire field, which should be based on 3D models. 
Seismic data recorded during seismic exploration can carry information about various geological, petrophysical, and geotechnical features. This suggests that formation's physical and mechanical properties can be estimated using seismic data and calibrated against log data which are more reliable. Using seismic data allows interpolation and extrapolation between and beyond sparse well data. Seismic attributes, extracted from seismic traces through different mathematical methods, reflect intrinsic characteristics of seismic information. Seismic attributes are more sensitive to change in formation parameters and can be used to predict geologic information since spatial changes of rocks' properties result in changes of seismic attributes which reflect geometry, kinematics, dynamics, and statistical characteristics of seismic information (Chen and Sidney 1997, Schmitt 1999, Hart and Balch 2000, Neves et al. 2004, Walker et al. 2005). As a broad generalization, time-dependent attributes provide structural information, whereas amplitude-derived attributes provide stratigraphic and reservoir information (Brown 1996). Frequency derived attributes are not yet well understood but there is a widespread optimism that they will provide additional useful reservoir information. Most attributes are derived from the normal stacked and migrated seismic data but variations of amplitude as a function of angle of incidence (and hence source to receiver offset) provides a further source of information (Chen and Sidney 1997).

The aim of this paper is to use seismic attributes of a 2D seismic data belonging to an offshore field located in southern part of Iran in order to predict shear wave velocity.

\section{SEISMIC ATTRIBUTES}

During the 1970s and 1980s, the most commonly used attributes in petroleum exploration were amplitude-based instantaneous ones. However, in the 1990s, seismic attribute technology has dramatically advanced in several directions from single-trace instantaneous attribute to more complex multitrace seismic event attribute extractions. With increasing growth of seismic attributes over the past decades, researchers attempted to classify them into various categories to highlight their goals and applications. For instance, Sheriff (2002) in his encyclopedic dictionary of geophysics has provided 153 lines to attributes, complex trace analysis, and hydrocarbon indicators, plus a full-page figure of complex trace analysis. Cosentino (2001) listed characteristics that can be identified by attributes, such as structures (e.g., horizon depth, reservoir thickness, and faults), internal architectures (heterogeneity), petrophysical properties (e.g., porosity and permeability), and hydrocarbon properties (e.g., production, thermodynamics, etc.). Taner et al. (1994) have divided attributes into two general categories: geometrical and physical ones. According to them, the objective of geometrical attributes is to enhance the 
visibility of the geometrical characteristics of seismic data. Physical attributes are related to physical parameters of the subsurface and can be used for identification of lithology. Brown (2004) classified attributes using a tree structure with time, amplitude, frequency, and attenuation as the main branches, which further branch out into post-stack and pre-stack categories. He indicated that time attributes provide information on structure, whereas amplitude attributes provide information on stratigraphy and reservoir. Chen and Sidney (1997) provided a classification based on wave kinematic/ dynamic categories and geologic reservoir feature categories. Barnes (1997) developed a classification of complex-trace attributes depending on the relationship among different attributes and seismic data. Liner et al. (2004) classified seismic attributes into general and specific categories. General attributes measure geometric, kinematic, dynamic, or statistical features derived from seismic data. They included reflector amplitude, reflector time, reflector dip and azimuth, complex amplitude and frequency, generalized Hilbert attribute, illumination, edge detection/coherence, amplitude versus offset (AVO), and spectral decomposition. These general attributes are based on either physical or morphological characteristics of the data tied to lithology or geology and are therefore generally applicable from basin to basin around the world (Meldahl et al. 2001).

In this paper, seismic attributes are classified into the four distinct categories:

1) Qualitative attributes, such as coherency and perhaps instantaneous phase or instantaneous frequency, which are promising for highlighting spatial patterns such as faults or facies changes. However, it is difficult to relate these attributes directly to a logged reservoir property like porosity or thickness, and thus these attributes are not normally used to quantify reservoir properties.

2) Quantitative attributes, such as zero phase amplitude, relative impedance and absolute impedance which are the most useful attributes for quantitative reservoir characterization.

3) Interval attributes are used to quantify a window of seismic data usually containing more than one peak or trough. Most seismic attributes fall into this category. Examples of interval attributes are the number of zero crossings, average energy, and dominant frequency. These attributes are frequently used when reservoir seismic reflections are so discontinuous that it is impossible to pick the same peak or trough on all traces. An interval attribute is analogous to a well log cross section with a number of thin, discontinuous sands that cannot be correlated with any certainty.

4) AVO attributes are those that are generated using a reflection's prestack amplitudes. Examples of pre-stack attributes are AVO gradient, AVO intercept, near amplitude, and far amplitude. The 3D pre-stack attributes 
have only become available recently with the advance of pre-stack time migrations. Pre-stack attributes have a lot of promises, but are beyond the scope of this paper to be presented in details.

\section{THE OFFSHORE FIELD AND AVAILABLE DATA}

The analysis in this paper is based on the data from an offshore field which is located at $90 \mathrm{~km}$ distance from Kharg Island, South Iran. The field is a NE-SW trending, elongated anticline, with dimensions of approximately $100 \mathrm{~km}^{2}$ in Burgan formation. The structure has a pronounced southern culmination and is faulted along its crest. A significant crestal collapse is present over the northern culmination that has a lower structural relief than the southern one. Uncertainty related to the depth of the flanks of the structure exists due to a lack of velocity data. The faults do not extend across the entire structure, and reservoir continuity and connectivity is expected to be maintained within the oil column resulting in a field wide common oil water contact (OWC) and pressure regime. The minor displacement along the faults combined with the high sand content limit the potential for the development of fault seals. However, an uncertainty exists on the sealing potential of individual faults. Some faults may seal and most faults are expected to form partial flow barriers resulting in tortuous flow paths across faults. The

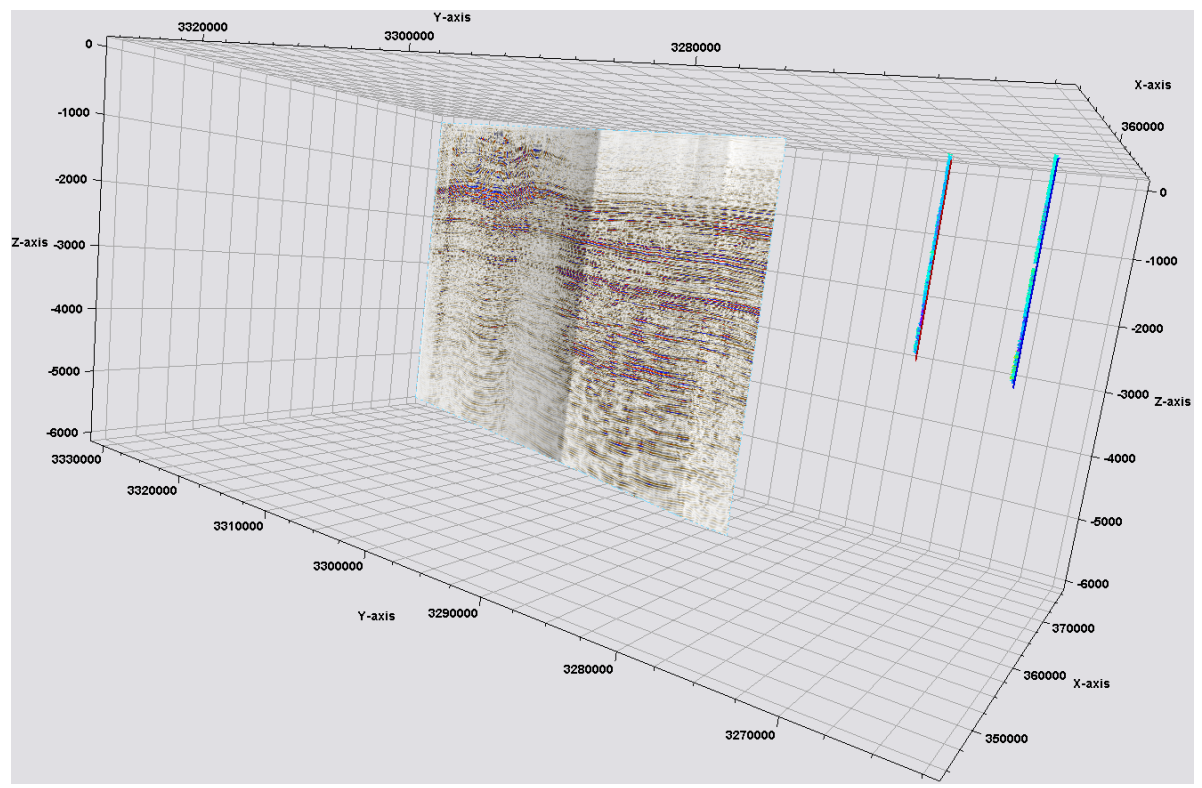

Fig. 1. The 2D seismic data as well as two wells used for seismic attribute extraction and modeling. 


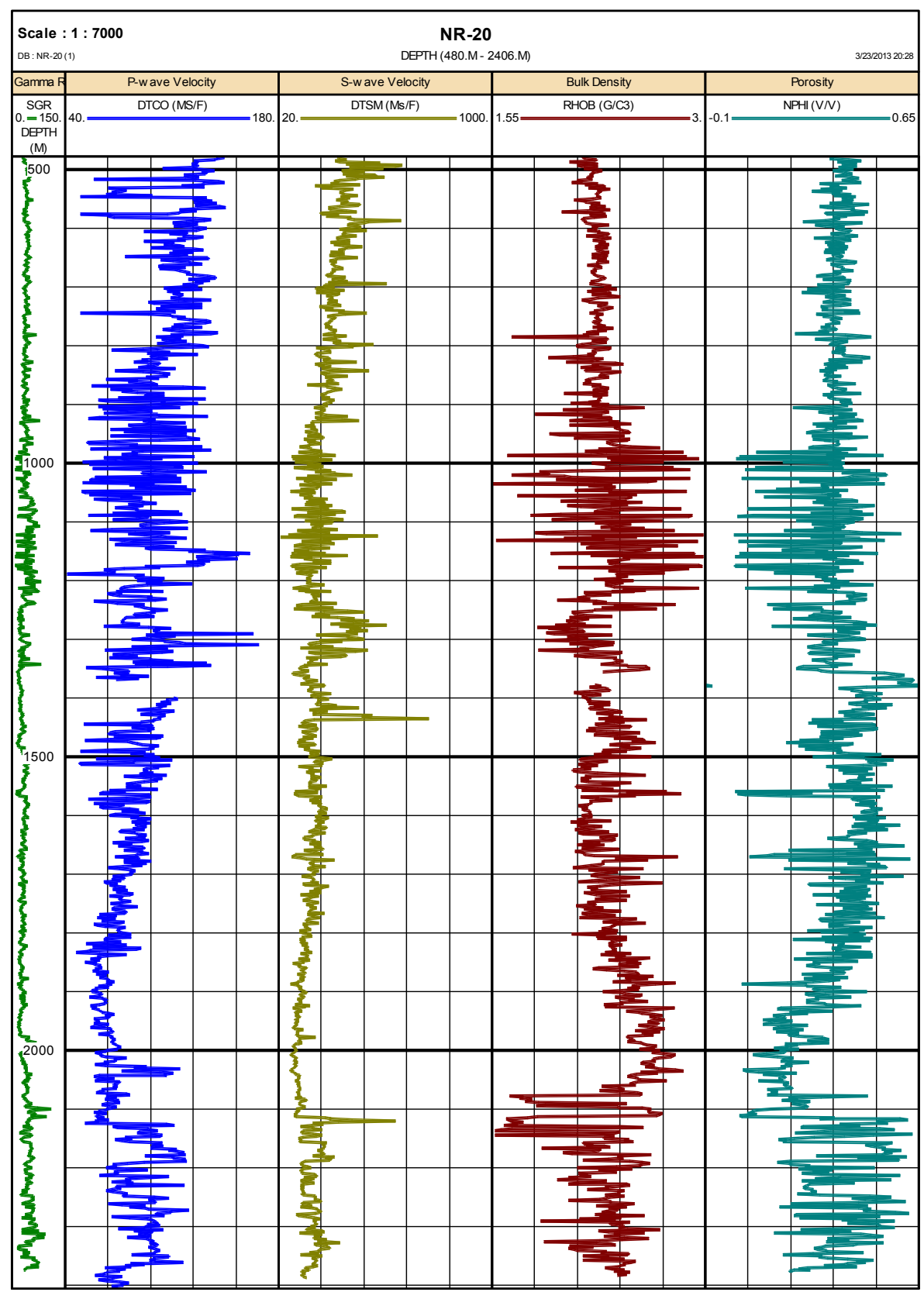

Fig. 2. Sonic compression and shear transit time (in British unite), density, and porosity logs corresponding to well NR-20. Colour version of this figure is available in electronic edition only. 


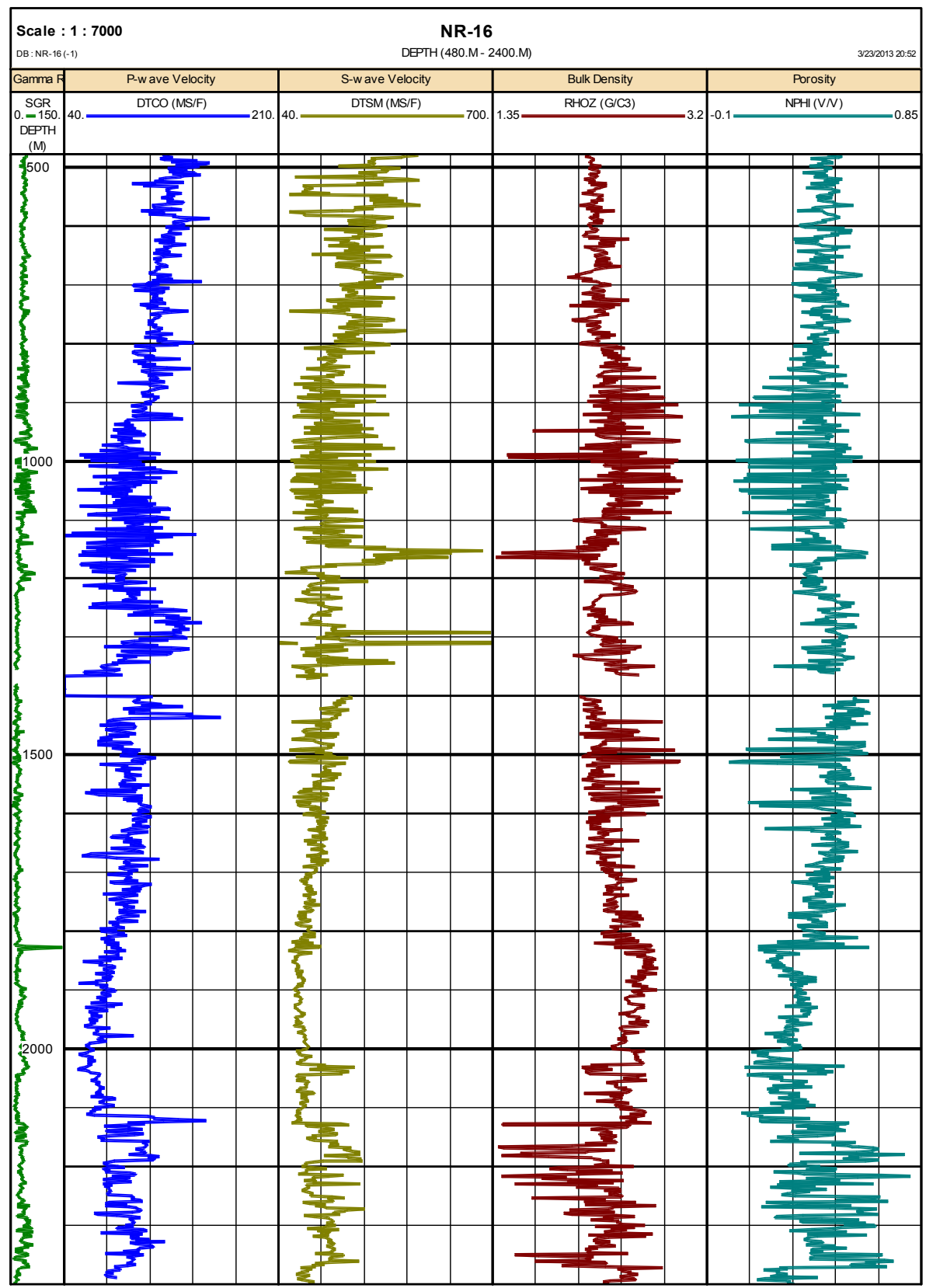

Fig. 3. Sonic compression and shear transit time (in British unite), density, and porosity logs corresponding to well NR-16. Colour version of this figure is available in electronic edition only. 
reservoir is heterogeneous and has uncertainties related to the actual location and correlatability of the good quality sands. Seismic and well log data belonging to this field were used in this study.

The studied area underwent a seismic survey over an area of about $200 \mathrm{~km}^{2}$. The two released final volumes (Spike and Gapped Deconvolution) showed high quality data. For the purpose of this study, a specific postmigration reprocessing was performed on seismic data. The spike deconvolution, spectral whitening, stratigraphic deconvolution, and notch dimensional spatial filter in the frequency domain were applied to improve the vertical resolution and to attenuate the acquisition footprint. Figure 1 shows $2 \mathrm{D}$ seismic line as well as the two wells used for the purpose of this study.

Two wells in this field, known as NR-16 and NR-20, were used for this study. Both wells contain shear and compression wave velocity data together with porosity and density logs. Well log datasets were considered to study the quantitative relationships between acoustic and litho-petrophysical properties and to support seismic lithology activities (both inversion and calibration). At the same time, a set of acoustic and petrophysical curves, including the generated synthetic seismograms, were used to correlate well and seismic information. Figures 2 and 3, respectively, present the available well logs corresponding to these two wells which were used in this study.

In this paper, the seismic attributes used to construct the shear wave model were extracted from stacking trace of borehole-side seismic traces by considering a specific neighborhood distance. In the first place, the timedepth correspondence relationship between seismic and well log data must be determined using acoustic log data of a drilled well to calibrate horizons accurately. With the exception of instantaneous attributes, choosing the size of time-limited moving window has a significant impact on calculating attributes. Practical attempts indicated that an appropriate size range for time window is $1100-1400 \mathrm{~ms}$.

\section{SEISMIC ATTRIBUTES SELECTION}

A good seismic attribute is either directly sensitive to the desired geological property of the formations or allows us to define the structural environment to infer features of interest. In this paper, the challenge was to select the most relevant attributes as well as an appropriate integration technique to model shear wave velocity using seismic data. The three most common prediction methods used in industry today are regression, geostatistics, and neural networks. Each method requires making an inference (prediction) from the seismic attribute(s) based on its relationship to much sparser information measured at well locations. In this paper, regression and neural networks methods were used to predict shear wave velocity using seismic attributes. 
The basic data integration process used in this paper to integrate seismic attributes for modeling shear wave velocity is divided into four steps (Uden et al. 2003):

1) Calibration: well data provides high-resolution, depth related local information, whereas seismic data provide spatially dense, but vertically lower resolution, time related information. Calibration is the first and most critical step in the process and the data must be calibrated both vertically and laterally.

2) Selection of seismic attribute(s): the primary objective is to identify those attribute(s) that works best as a predictor for the reservoir property of interest. However, care must be taken when choosing the seismic attribute, because it is not unusual to find spurious or false correlations that do not reflect any physical basis for the relationship. The probability of finding a false correlation increases with the number of seismic attributes and is inversely proportional to the number of data control points (i.e., number of wells selected for modeling).

3) Prediction: the areal distribution of the variable of interest is mapped by integrating the well data and the seismic attribute. The prediction step is typically done by either linear or non-linear regression models, neural networks, or using a geostatistical methods.

4) Cross-validation: this is the systematic removal of wells, one-by-one, and re-estimating their values based on the model selected. Cross-validation is not always performed, but it does provide a means to validate the contribution of the secondary information to improve the prediction.

Considering the above steps, after calibration and quality control of the wells and seismic data, 35 attributes were extracted from seismic data including instantaneous amplitude, instantaneous phase, instantaneous frequency, root mean square amplitude, average and dominant frequency, amplitude weighted frequency, chaos, amplitude envelope, concentrated correlation value, derivative, etc. (Todoeschuck and Jensen 1988, Turcotte 1989, Walden and Hosken 1985, Zeng et al. 1995). Table 1 lists the seismic attributes extracted from seismic data in present study. Figure 4 shows four of these attributes used to build the shear wave velocity log.

According to Chao et al. (2009), attributes combination which are sensitive and relevant to given problems must be selected to improve efficiency, accuracy, and precision of prediction. In this study, to select the most relevant attributes combination appropriate for predicting shear wave velocity as well as building a 2D shear wave model, independent component analysis (ICA) was employed.

ICA is a dimensionality reduction technique used to transform the data and reveal the most relevant features of any type of system (Comon 1994). ICA is a technique for extracting a smaller set of variables with less redun- 
Table 1

Seismic attributes extracted from seismic data in current study

\begin{tabular}{|c|l|}
\hline Number & \multicolumn{1}{|c|}{ Seismic attributes } \\
\hline 1 & Integrated absolute amplitude \\
2 & Root-mean-square amplitude \\
3 & Reflection intensity \\
4 & Average frequency \\
5 & Instantaneous amplitude \\
6 & Instantaneous frequency \\
7 & Instantaneous phase \\
8 & Instantaneous quality \\
9 & Instantaneous square amplitude \\
10 & Weighted instantaneous frequency \\
11 & Energy of reflection strength \\
12 & Polarity of reflection strength \\
13 & Time \\
14 & Trace gradient \\
15 & Frequency bandwidth of amplitude spectrum \\
16 & Apparent polarity \\
17 & Cosine instantaneous phase \\
18 & Quadrature amplitude \\
19 & Autocorrelation function \\
20 & Derivative \\
21 & Amplitude weighted cosine phase \\
22 & Average energy \\
23 & Concentrated correlation value \\
24 & Quadrature trace \\
25 & Apparent polarity \\
26 & Dominant frequency \\
27 & Energy of assigned bandwidth \\
28 & Frequency of cumulative energy \\
29 & Autoregressive coefficients of five order \\
30 & Amplitude weighted frequency \\
31 & Amplitude weighted phase \\
33 & Chaos \\
\hline
\end{tabular}


dancy from high-dimensional data sets to retain as much of the information as possible (Lee 1998). Determination of linear combinations of variables, feature extraction, dimensionality reduction, visualization of multidimensional data, and identification of underlying variables are of the most important abilities of ICA (Hyvärinen 1999a). This method decorrelates the input signals and reduces higher-order statistical dependencies (Hyvärinen 1999b).

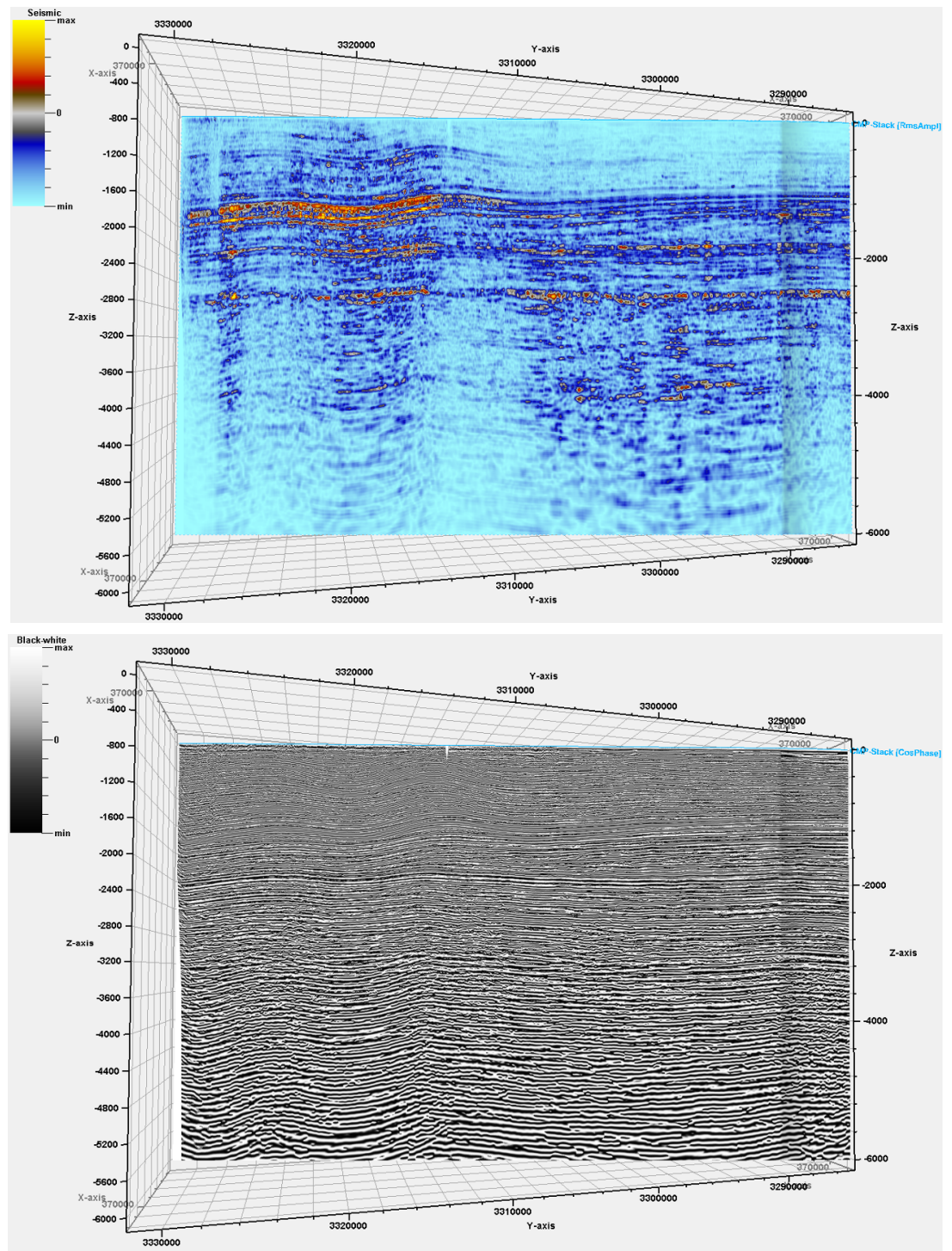

Fig. 4. Continued on next page. 


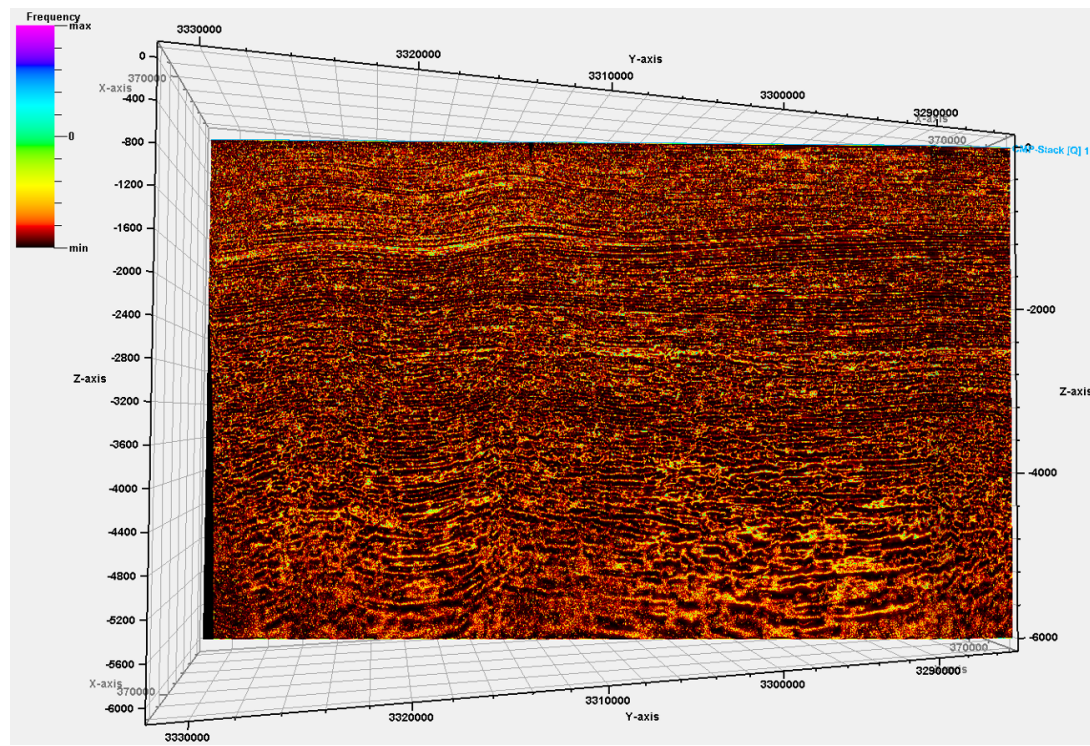

(c)

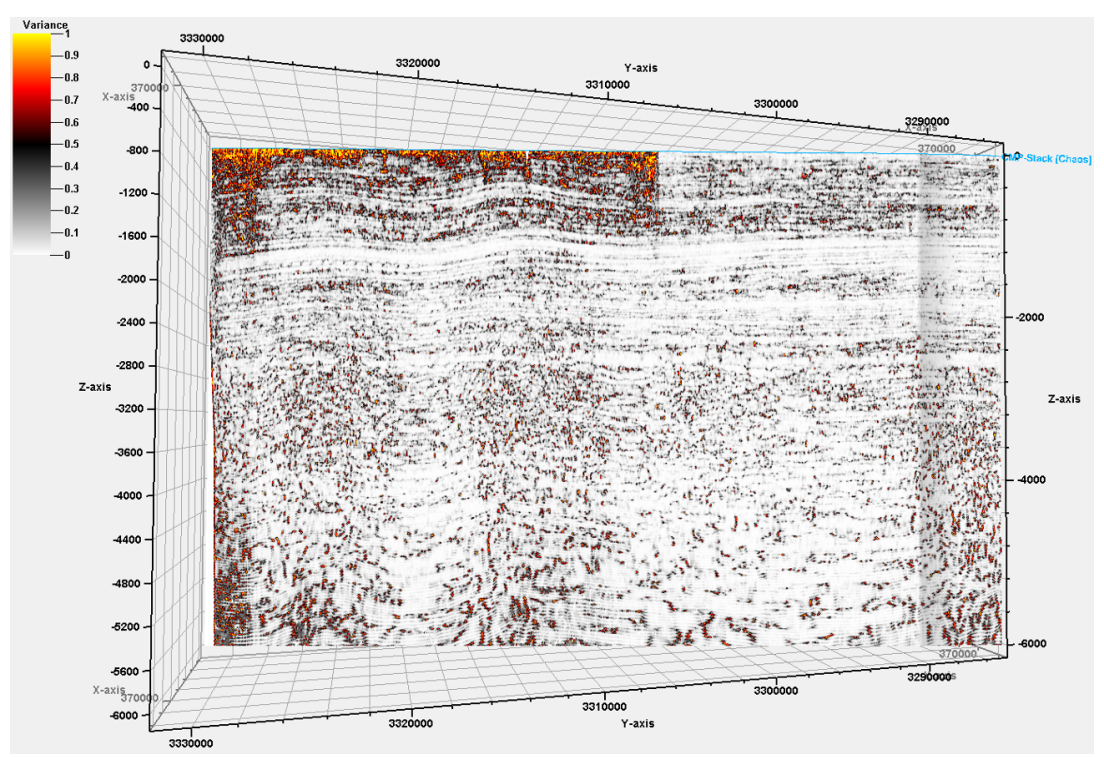

(d)

Fig. 4. Four extracted attributes: root mean square amplitude (a), amplitude weighted cosine phase (b), instantaneous quality (c), and chaos (d). Colour version of this figure is available in electronic edition only.

Although our hypothesis is that the technique may have utility to multiattributes selection analysis, it is not clear whether the ICA algorithm can be used in analysis like this since it rests upon the determination of a non-linear 
optimization function that separates sources in the input (Hyvärinen and Oja 2000). Since the algorithm of ICA has been extensively presented in the literatures, we brought the theoretical background of the technique in the Appendix section.

Thus, ICA technique was used in the first step to determine the most appropriate attributes among 35 extracted attributes (see Table 1). Correlation matrix, scree plot, and rotated matrix were obtained after analysis as they are often used to represent the output of such analysis. The results obtained revealed that extracted seismic attributes can be categorized into four components, while component 1 contains the attributes of interest related to shear wave velocity log. Table 2 gives the rotated matrix obtained after applying the ICA.

Given in Table 2, the 27 attributes in component 1 have possibly unknown relationship with shear wave velocity logs. This means that perhaps these 27 attributes can be used in predicting the shear wave velocity log as well as making a model of shear wave using seismic data. To model the shear wave log using these attributes, a multivariate regression analysis was used. This method is an extension of the linear regression analysis incorporating additional independent variables in the predictive equation (Khademi et al. 2010). Applying regression analysis indicated that using the 27 attributes, the shear wave data can be predicted with a correlation coefficient of 0.66 and an average error of $61.76 \mu \mathrm{s} / \mathrm{f}$. Figure 5 shows the original and modeled shear wave velocity log obtained using regression analysis. As shown in this figure, the modeled log is not as good as it is expected. Figure 6 shows the performance of regression analysis in prediction of shear wave $\log$ of well NR-20 using 27 attributes.

According to published works in this area of research, possible explanation for having a weak correlation is spurious correlations of seismic attributes (Sheriff 2002, Barnes 2000). As a matter of fact, as we generated more seismic attributes, there is a greater chance of observing at least one large spurious (false) correlation value. Kalkomey (1997) discussed the potential risks when using seismic attributes as predictors for reservoir properties and illustrated the impact of spurious correlations. According to him, the probability of a spurious correlation depends solely on $R$ (i.e., the magnitude of the spurious sample correlation) and $n$, the number of well measurements, based on the assumption of random sampling. The problem of spurious correlations is only enhanced when more than one attribute are considered at a time. Because many attributes contain the same information, it is important to select independent attributes for multivariate analysis. Barnes (2000) advised that independent attributes should be used for reservoir identification and characterization. Kalkomey (1997) argued the use those attributes that 
Table 2

Rotated component matrix showing the number of components extracted using ICA

\begin{tabular}{|c|c|c|c|c|c|}
\hline $\begin{array}{c}\text { Locus } \\
\text { no. }\end{array}$ & Seismic attributes & \begin{tabular}{|c|} 
Compo- \\
nent 1 \\
\end{tabular} & \begin{tabular}{|c|} 
Compo- \\
nent 2 \\
\end{tabular} & $\begin{array}{c}\text { Compo- } \\
\text { nent } 3\end{array}$ & $\begin{array}{c}\text { Compo- } \\
\text { nent } 4 \\
\end{array}$ \\
\hline 1 & Integrated absolute amplitude & 0.73 & 0.130 & 0.040 & 0.240 \\
\hline 2 & Root-mean-square amplitude & 0.71 & 0.032 & -0.012 & 0.300 \\
\hline 3 & Reflection intensity & 0.62 & 0.090 & 0.170 & -0.040 \\
\hline 4 & Average frequency & 0.66 & -0.120 & 0.160 & 0.070 \\
\hline \multirow[t]{4}{*}{5} & Instantaneous amplitude & 0.77 & 0.016 & -0.420 & 0.201 \\
\hline & Instantaneous frequency & 0.18 & 0.025 & 0.618 & 0.110 \\
\hline & Instantaneous phase & 0.12 & 0.110 & 0.020 & 0.770 \\
\hline & Instantaneous quality & 0.11 & 0.110 & -0.160 & 0.830 \\
\hline 6 & Instantaneous square amplitude & 0.70 & -0.010 & 0.270 & 0.102 \\
\hline 7 & Weighted instantaneous frequency & 0.59 & 0.090 & -0.160 & 0.190 \\
\hline 8 & Energy of reflection strength & 0.67 & -0.150 & 0.250 & 0.030 \\
\hline 9 & Polarity of reflection strength & 0.61 & 0.120 & -0.013 & 0.040 \\
\hline \multirow[t]{3}{*}{10} & Time & 0.77 & -0.210 & 0.330 & 0.210 \\
\hline & Trace gradient & -0.25 & 0.845 & 0.070 & 0.120 \\
\hline & $\begin{array}{l}\text { Frequency bandwidth of amplitude } \\
\text { spectrum }\end{array}$ & 7 & 0.040 & -0.180 & 0.660 \\
\hline 11 & Apparent polarity & 0.63 & 0.220 & 0.240 & 0.060 \\
\hline 12 & Cosine instantaneous phase & 0.71 & 0.310 & -0.210 & 0.023 \\
\hline 13 & Quadrature amplitude & 0.74 & -0.090 & 0.120 & 0.270 \\
\hline 14 & Autocorrelation function & 0.60 & 0.250 & -0.014 & 0.032 \\
\hline 15 & Derivative & 0.55 & 0.120 & 0.200 & 0.220 \\
\hline \multirow[t]{3}{*}{16} & Amplitude weighted cosine phase & 0.57 & 0.060 & -0.160 & 0.150 \\
\hline & Average energy & 0.22 & 0.180 & 0.854 & -0.290 \\
\hline & Concentrated correlation value & -0.17 & 0.790 & -0.013 & 0.034 \\
\hline 17 & Quadrature trace & 0.68 & -0.020 & 0.250 & 0.045 \\
\hline 18 & Apparent polarity & 0.77 & 0.110 & 0.310 & -0.210 \\
\hline 19 & Dominant frequency & 0.65 & 0.110 & -0.340 & 0.044 \\
\hline 20 & Energy of assigned bandwidth & 0.69 & 0.260 & -0.140 & 0.055 \\
\hline \multirow[t]{2}{*}{21} & Frequency of cumulative energy & 0.79 & 0.080 & 0.340 & -0.440 \\
\hline & $\begin{array}{l}\text { Autoregressive coefficients } \\
\text { of five order }\end{array}$ & 3 & 0.010 & 0.190 & 0.861 \\
\hline 22 & Amplitude weighted frequency & 0.71 & 0.250 & 0.170 & 0.120 \\
\hline 23 & Amplitude weighted phase & 0.58 & 0.012 & -0.090 & 0.220 \\
\hline 24 & Chaos & 0.57 & 0.018 & 0.300 & -0.170 \\
\hline 25 & Amplitude envelope & 0.78 & -0.210 & 0.270 & 0.010 \\
\hline 26 & Reflection acoustic impedance & 0.74 & -0.110 & 0.260 & 0.013 \\
\hline \multirow[t]{2}{*}{27} & Second derivative & 0.65 & 0.012 & -0.070 & 0.280 \\
\hline & Shear wave velocity log data & 0.70 & -0.220 & 0.188 & 0.098 \\
\hline
\end{tabular}

Explanations: Bolded are all the components having high correlation with shear wave velocity $\log$. 


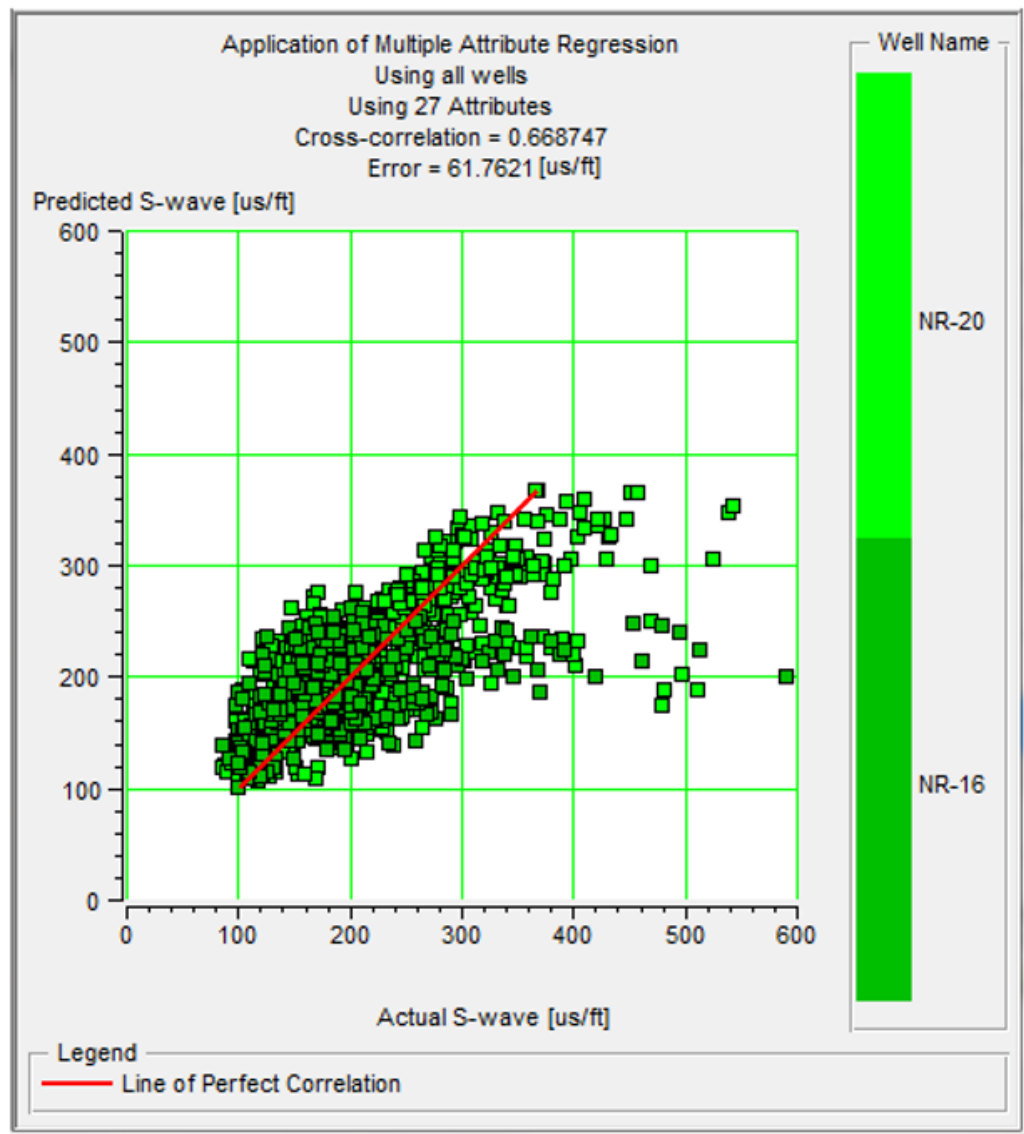

Fig. 5. Correlation between actual and predicted shear wave velocity obtained by first step regression analysis.

are indicator of physical properties or features of interest in a reservoir similar to the one we study here. Sheriff (2002) suggested using each attribute for capturing only one type of physical property, which can then be combined intelligently using geostatistics, neural networks or other multiattribute analysis tools.

Amplitude, phase, and frequency are fundamental parameters of seismic wavelet and from these few all other attributes are derived, either singly or in combinations, and many of the new attributes duplicate each other because of the nature of the computations. For example, bi-variate scatter plots of various attributes in this study revealed that amplitude weighted cosine of phase and second derivatives, amplitude envelope and amplitude weighted 


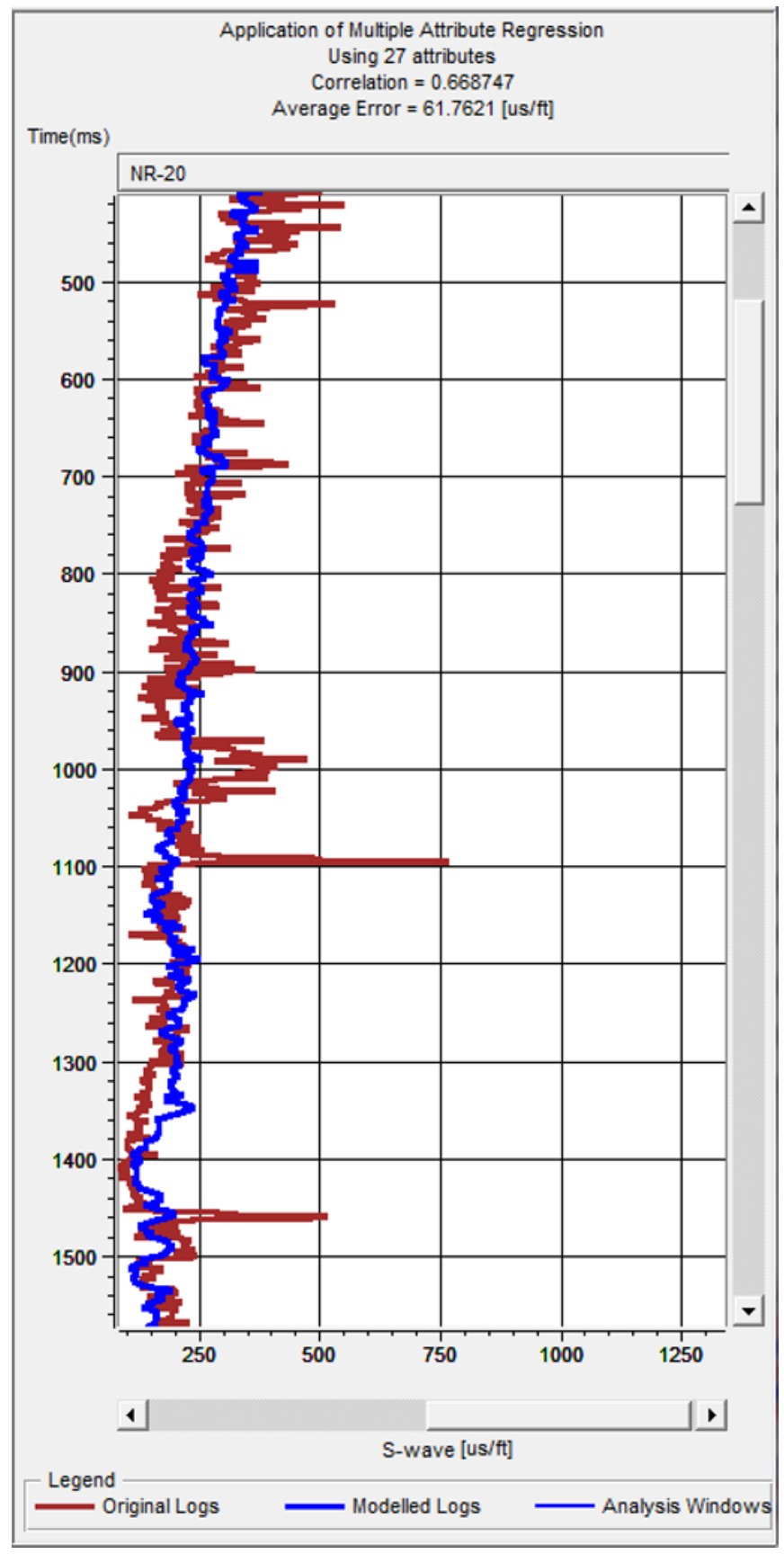

Fig. 6. Comparison of original and modeled $S$-velocity log obtained using regression analysis. Colour version of this figure is available in electronic edition only. 

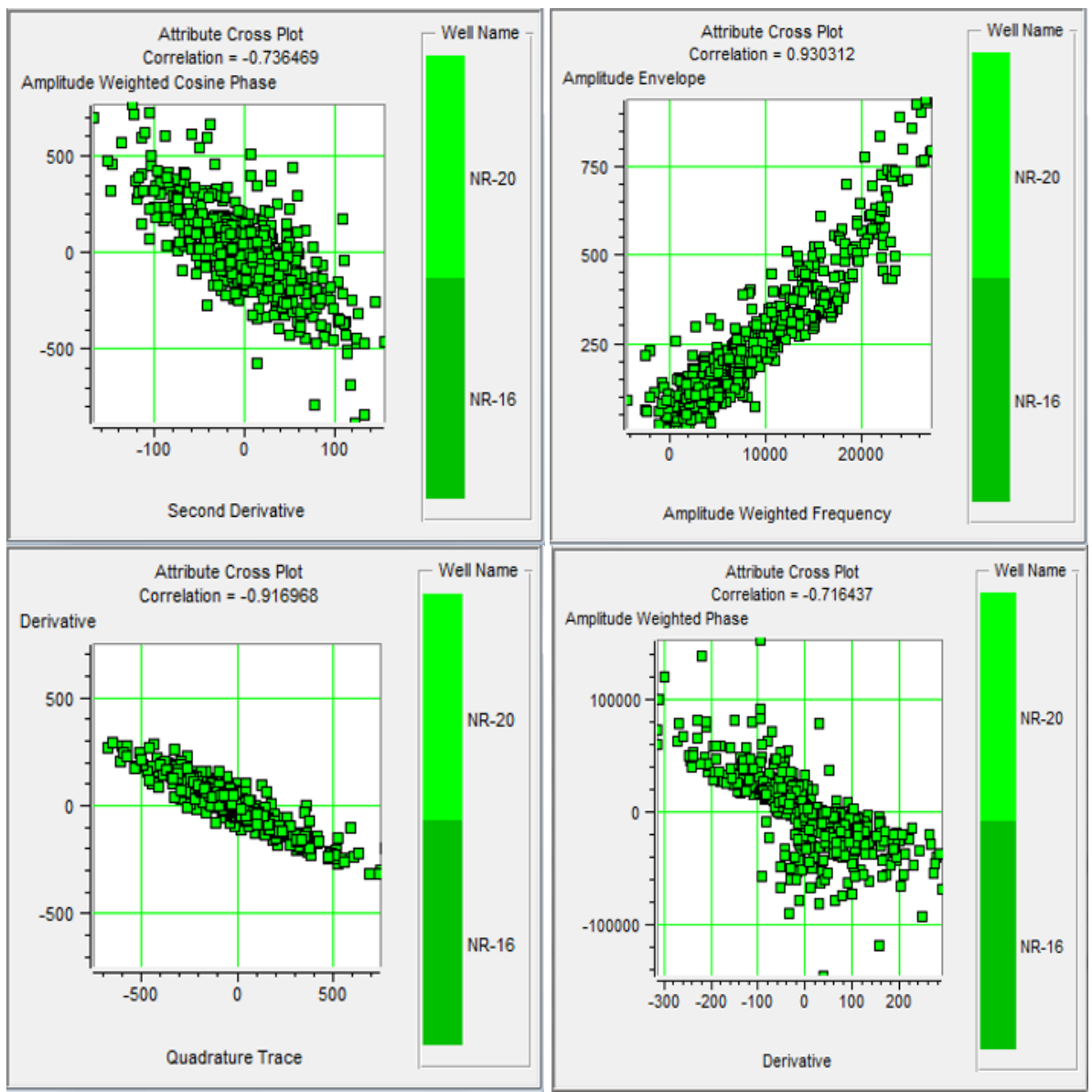

Fig. 7. These plots show the high correlation between the attributes already selected by ICA.

frequency, derivative and quadrature trace, amplitude weighted phase and derivative, RMS amplitude and energy of reflection strength, amplitude weighted phase and instantaneous phase, amplitude weighted cosine phase and cosine instantaneous phase, average frequency and time, amplitude weighted phase and quadrature trace have a high correlation with each other and contain the same information. Thus, one of these attribute should be discarded from regression analysis since independent attributes need to be selected. Figure 7 represents those attributes which showed to have a high correlation with each other.

After selecting independent attributes, the number of attributes was reduced to 17. Figure 8 shows some of the independent attributes selected for 

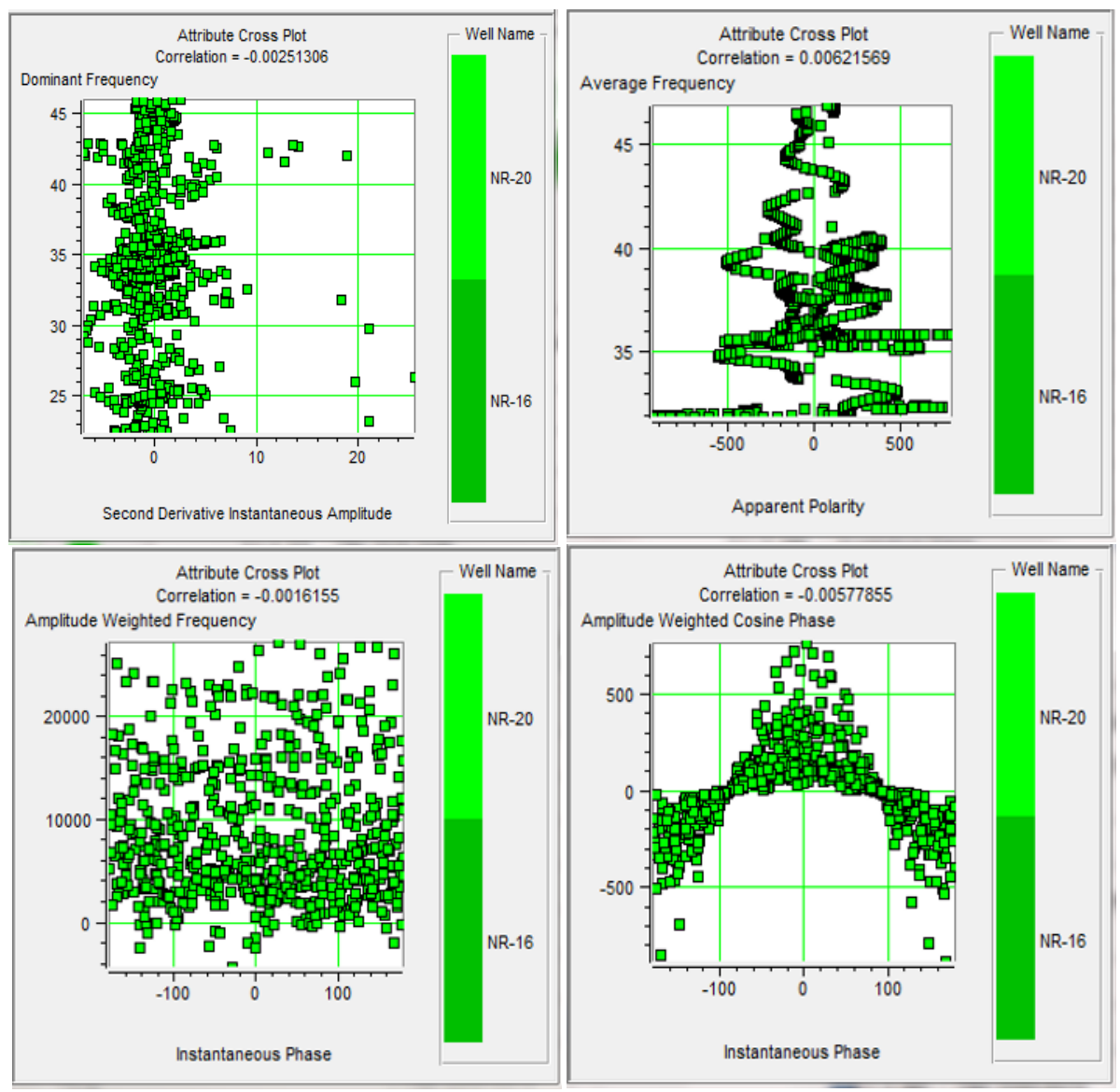

Fig. 8. Independent attributes selected for regression analysis.

the second regression analysis. As shown in this figure, only attributes with low correlation coefficient (i.e., independent) were selected for subsequent analysis. Considering these independent attributes, regression analysis was performed for the second time. The results revealed that independent attributes increased the correlation coefficient to 0.77 and decreased the average error to $45.23 \mu \mathrm{s} / \mathrm{f}$. Figure 9 shows the correlation coefficient and error of utilizing 17 independent attributes. The improvement gained is, however, inadequate, so further analysis was required accordingly. To achieve this, the use of independent attributes followed by a robust neural network technique in order to combine multiple attributes in a meaningful manner was exercised in the next step of this study. 


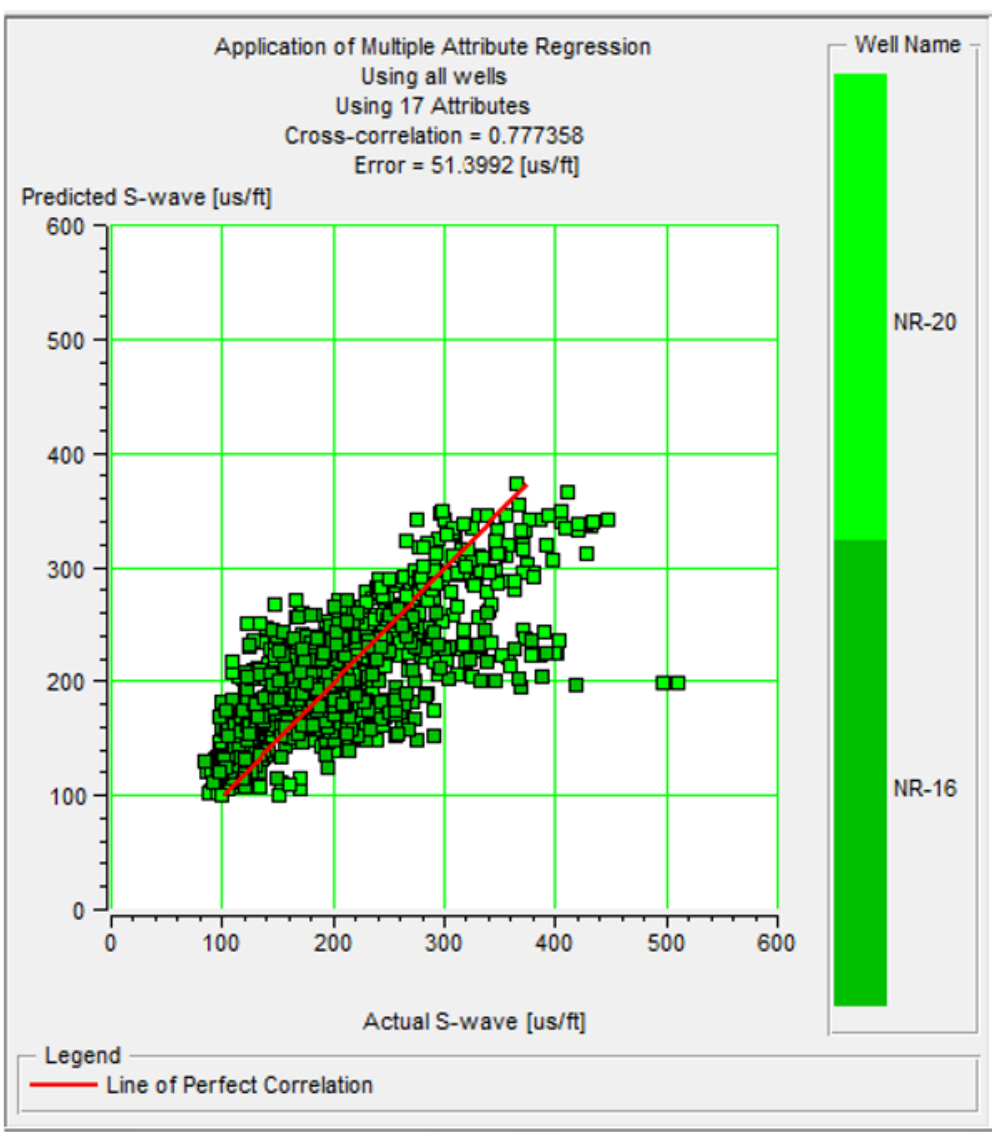

Fig. 9. Correlation between actual and predicted shear wave velocity obtained after second step regression analysis using 17 independent attributes.

\section{ARTIFICIAL NEURAL NETWORK}

The goal of artificial neural network (ANN) is developing a mathematical model in order to design an intelligent information processing system for classification or regression analysis (McCulloch and Pitts 1943). An adaptive neural network consists of a number of nodes connected through directional links, all or part of the nodes are adaptive which means the output of these nodes depends on modifiable parameters belonging to these nods.

Van der Baan and Jutten (2000) and Poulton (2002) have discussed the theory of neural networks and its applications in geophysical studies. Although neural network theory dates back to the mid-twentieth century, its applications to geophysics are relatively recent with the earliest papers date 
back to the late 1980's and early 1990's. The authors of early studies focused entirely on the application of multi-layer perceptron (MLP) neural network in first break picking and trace editing of seismic data (McCormack 1990, Upham and Carey 1991). More recent applications of neural networks in geophysics have one thing in common: they have become almost exclusively associated with the term "seismic attributes". A review of seismic attributes and their uses was given by Sheline (2005). The use of seismic attributes in neural network applications allows us to build the multidimensionality needed for the successful application of neural network technology. However, as pointed out by Sheline (2005), one should understand the geophysical implication of each attribute. The application of supervised attribute analysis for the prediction of reservoir parameters using the probabilistic neural network, general regression neural network, and radial basis function network has been shown by Hampson et al. (2001) and Russell et al. (2003). In this paper, multi-layer feed forward network (MLFN) is used to predict shear wave velocity log using seismic attributes. In the following sections, a brief description of the principles and structures of this network is firstly presented and then its application to map seismic attributes for shear wave velocity modeling is shown.

\subsection{Multi-layer feed forward neural network (MLFN)}

Multi-layer feed forward network (MLFN) is the classic neural network referred to as multi-layer perceptron (MLP). Supervised learning using the perceptron model was first presented by Rosenblatt (1958). It has the capability of solving nonlinear problems but its final answer is dependent on the initial guess of the weights. The first layer in the MLP is referred to as the input layer, the second layer as the hidden layer, and the third layer as the output layer. Between input and output layer, one or more hidden layers are possible but it is common to use one hidden layer with optimal number of nodes. Any function with a finite collection of points and any function that is continuous and bounded can be solved with 3 layers. The 3-layer model can handle many functions that do not have these criteria (Masters 1993). In the case of prediction using seismic attributes, the input to the MLFN is a vector of $M$ attributes value $x_{j}^{T}=\left[x_{1 j}, x_{2 j}, \ldots, x_{M j}\right]$, where $j=1, \ldots, N$, is the number of seismic samples. The output of the weighting and summation in first layer can be written as:

$$
y_{k j}^{(1)}=\sum_{i=0}^{M} w_{k i}^{(1)} x_{i j}=W^{(1) T} x_{j}, \quad k=1,2, \ldots, K .
$$

The input to the single perceptron in layer 3 can be written as: 


$$
y_{j}^{(2)}=\sum_{k=0}^{k} w_{k i}^{(2)} z_{k j}^{(1)}=w_{j}^{(2) T} z_{j}^{(1)}, \quad j=1,2, \ldots, N
$$

where $z_{k j}^{(1)}$ is nonlinear function that imposes to the output of layer 1; one of the most commonly used functions in MLFN is logistic function (Eq. 3) in which the output is constrained between -1 and +1 .

$$
f(x)=\operatorname{logist}(x)=\frac{1}{1+\exp (-x)} .
$$

The final output for MLFN can be written as:

$$
z_{j}^{(2)}=f^{(2)}\left(w^{(2) T} f^{(1)}\left(w^{(1) T} x_{j}\right)\right) .
$$

Weight of the network is computed using error back propagation algorithm in which errors are back propagated through the network and used to improve the fit between the actual output and the training value.

\subsection{Implementation of MLFN in this study}

As it was mentioned, a multi-layer feed forward network (MLFN) was used to predict shear wave velocity log using seismic attributes. The network used for this study was a multi-layer neural network with one hidden layer of sigmoid function containing 30 neurons and an output layer containing only one neuron with pureline function. Multiple layers of neurons with nonlinear transfer functions allow the network to learn nonlinear relationships between the inputs (i.e., seismic attributes) and output vector (i.e., shear wave velocity $\log$ ). Selection of weighting function for the attributes was done automatically by giving an initial guess of 0.5 and updating the weight through inversion process to reach the minimum error. The shear wave velocity log of well NR-20 was used for training the network, whereas the shear wave log of well NR-16 was considered to test the results of the trained network. The result of the training process using the above constructed MLFN is shown in Fig. 10.

As shown in Fig. 10, MLFN is able to predict shear wave velocity with correlation coefficient of 0.98 and an error of approximately $22 \mu \mathrm{s} / \mathrm{f}$. The results indicate the capability of this network in prediction process. However, the performance of this network yet needs to be validated through testing step. Therefore, the constructed network was tested using shear wave velocity log data of well NR-16 in order to show the efficiency of the network in prediction of unseen data. Figure 11 shows the correlation coefficient between the actual and predicted shear wave data of MLFN during testing step. 


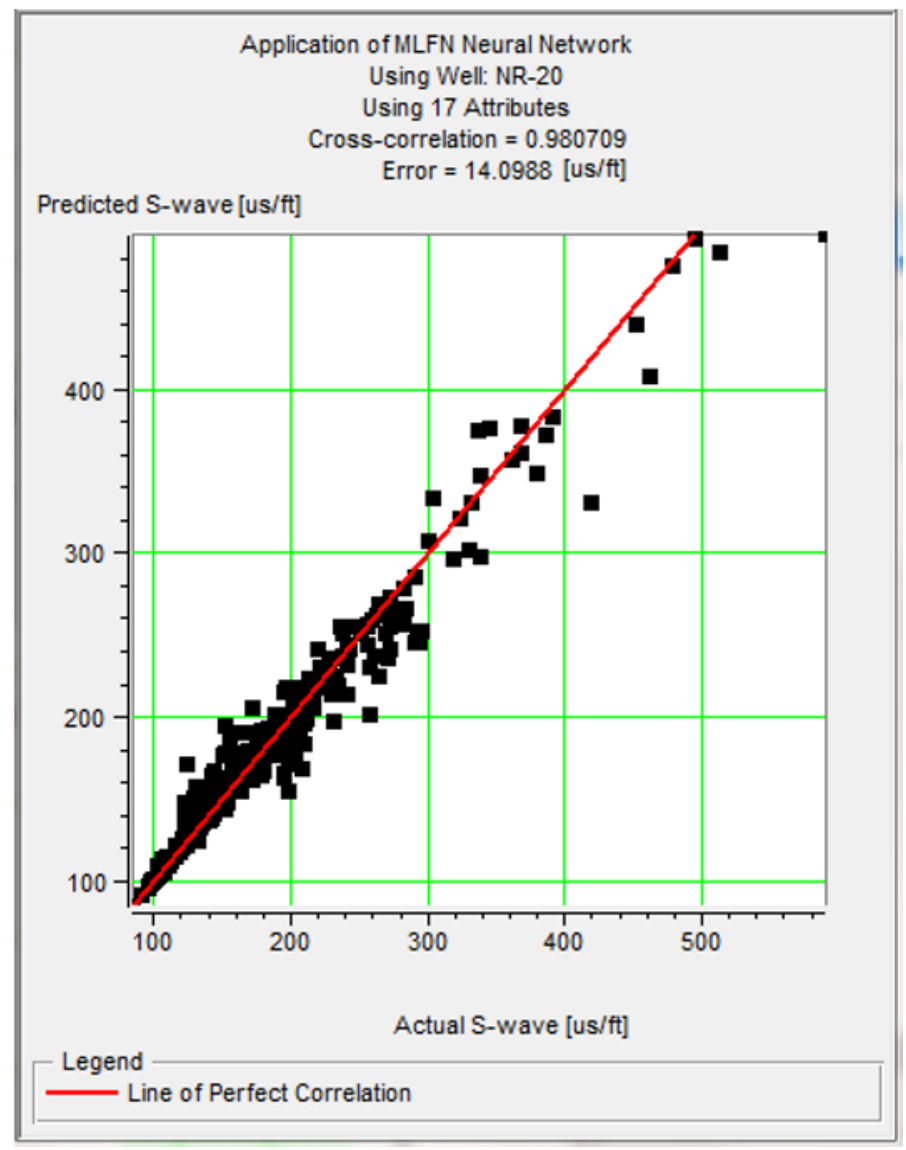

Fig. 10. Training of the MLFN using 17 attributes selected by ICA and regression analysis.

As shown in Fig. 11, the neural network built through training step is a high performance network which can be used to predict shear wave velocity log. Figure 12 shows the results of applying trained MLFN to predict shear wave velocity log corresponding to well NR-16.

As depicted in Fig. 11, the MLFN built during this study is able to provide a good estimation of unseen data for well NR-16. Therefore, this network can be utilized to build a 2D model of shear wave velocity data. Figure 13 shows the results presented by MLFN analysis after using this network to predict the shear wave velocity through the entire seismic data. Although the result shown in Fig. 13 is not as good as real processing of shear wave data carried out by employing 3-component geophones, it can 


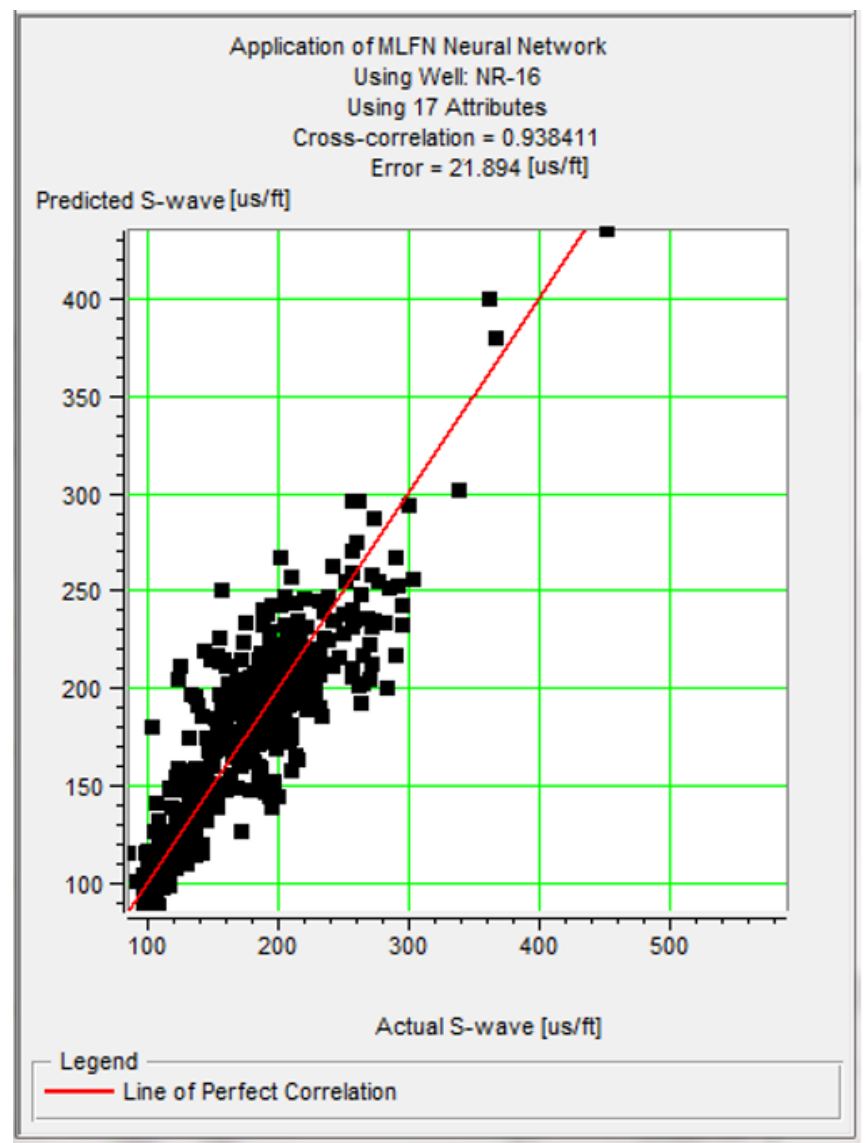

Fig. 11. Testing of the MLFN using 17 attributes selected ICA and regression analysis.

provide insight into the variation of shear wave through the earth while 1-component geophones are used for acquisition which is the most likely case in many hydrocarbon fields. The methodology presented in this paper can be used as asset for making 2D or 3D modeling of various properties of hydrocarbon reservoirs.

\section{CONCLUSIONS}

In this paper, attempts were made to show the applications of seismic attributes in prediction of shear wave velocity. It was shown that to select relevant attribute, a feature extraction method like independent component analysis (ICA) can be useful as long as the independency of extracted attributes is taken into consideration. Nonlinear relationship between seismic attributes 


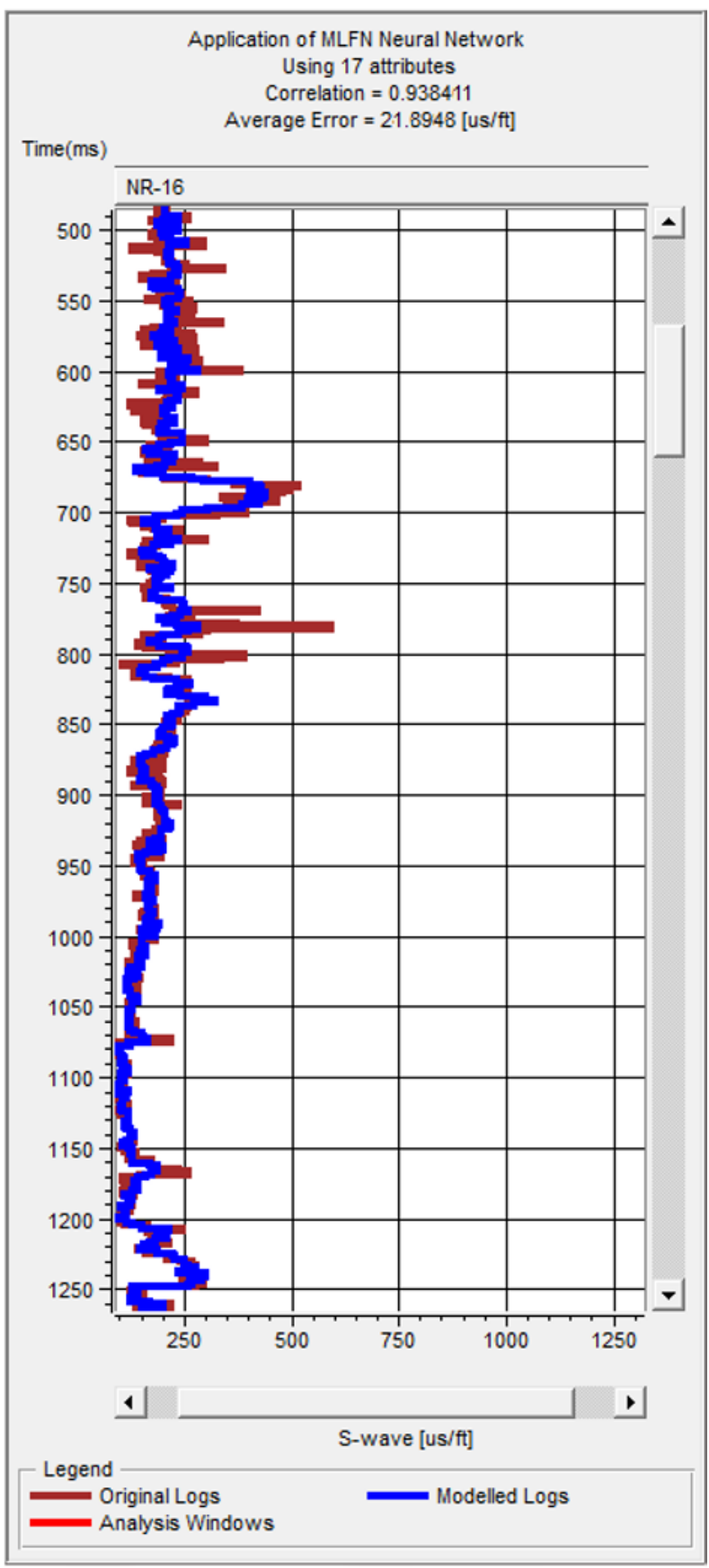

Fig. 12. Application of the trained MLFN to predict shear velocity log for well NR-16. Colour version of this figure is available in electronic edition only. 


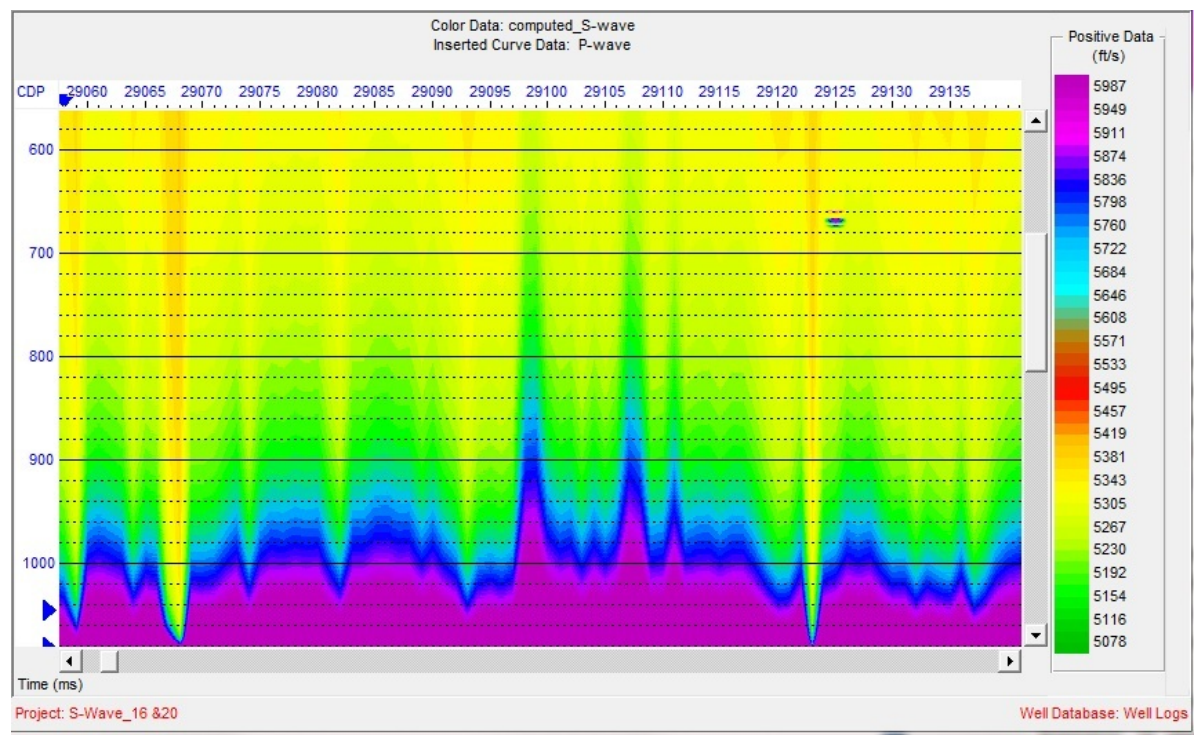

Fig. 13. The 2D model of shear wave velocity on the seismic data constructed from the MLFN analysis. Colour version of this figure is available in electronic edition only.

and property of interest was shown to be another point that should be taken into consideration. A high performance algorithm such as neural network can be used to solve the problem of nonlinearity of seismic attributes. The results presented indicated that multi-layer feed forward neural network (MLFN) can be a good network to map seismic attributes and providing a $2 \mathrm{D}$ model for shear wave velocity. The use of this $2 \mathrm{D}$ model may be enhanced by a better and robust algorithm like support vector machine. Finally, it was discussed that the model presented by the MLFN analysis should be assessed as it can provide insight into the variation of shear wave velocity in the subsurface layers.

\section{Appendix}

\section{Independent component analysis algorithm}

Independent component analysis of the random vector $x$ is defined as the process of finding a linear transform $S=W x$ such that $W$ is a linear transformation and the components $s_{i}$ are as independent as possible. They maxi- 
mize a function $F\left(s_{1}, \ldots, s_{m}\right)$ that provides a measure of independence (Hyvärinen 1999a). The individual component $s_{i}$ is independent when its probability distribution factorizes (when there is no mutual information between them) and can be written as

$$
f_{s}(s)=\prod_{s_{i}} f_{s_{i}}\left(s_{i}\right)
$$

The approach used to minimize the mutual information involves maximizing the joint entropy $H[g(s)]$. This is accomplished using a stochastic gradient ascent method, termed infomax. If the non-linear function $g$ is the cumulative density function of the independent components $s_{i}$, then this method also minimizes the mutual information. The procedure of transforming data in higher dimension has shown in Fig. A1.

Notice that the nonlinear function $g$ has chosen without knowing the cumulative density functions of the independent components. In case of a mismatch, it is possible that the algorithm does not converge to a solution (Bell and Sejnowski 1997). A set of non-linear functions has been tested and it has been found that super Gaussian probability distribution functions converge to an ICA solution when the joint entropy is maximized. The optimization step in obtaining the independent components relies on changing the weights according to the entropy gradient that can be expressed as:

$$
\Delta W \propto \frac{\partial H(y)}{\partial W}=E\left[\frac{\partial \ln |J|}{\partial W}\right],
$$

where $E$ is the expected value, $y=\left[g\left(s_{1}\right) \ldots g\left(s_{n}\right)\right]^{T}$ and $|J|$ is the absolute value of the determinant of the Jacobian matrix of the transformation from $x$ to $y$. From this formula, $\Delta W$ can be calculated using the equation

$$
\Delta W=\left(W^{T}\right)^{-1}+\left(\frac{\frac{\partial g(s)}{\partial s}}{g(s)}\right) x^{T} .
$$

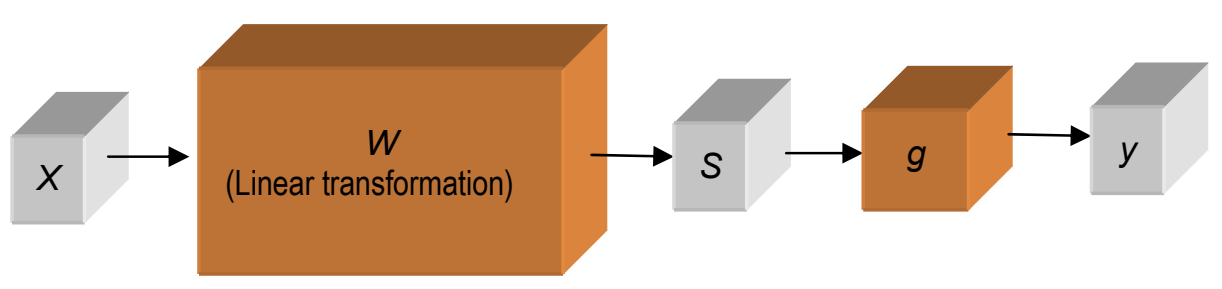

Fig. A1. Mechanism of data transformation based on the ICA algorithm. 
Equation A3 is involved in the matrix inversion, and hence an alternative formulation is preferred involving only simple matrix multiplication and addition. This formulation is written as (Bell and Sejnowski 1997, Lee 1998):

$$
\Delta W \propto \frac{\partial H(y)}{\partial W} W^{T} W=\left(\left(W^{T}\right)^{-1}+\left(\frac{\frac{\partial g(s)}{\partial s}}{g(s)}\right) x^{T}\right) W^{T} W=W+\left(\frac{\frac{\partial g(s)}{\partial s}}{g(s)}\right) s^{T} W .
$$

\section{References}

Ameen, M.S., B.G.D. Smart, J.M. Somerville, S. Hammilton, and N.A. Naji (2009), Predicting rock mechanical properties of carbonates from wireline logs (A case study: Arab-D reservoir, Ghawar field, Saudi Arabia), Mar. Petrol. Geol. 26, 4, 430-444, DOI: 10.1016/j.marpetgeo.2009.01.017.

Barnes, A.E. (1997), Genetic classification of complex seismic trace attributes. In: Proc. 67th Annual Meeting, Society of Exploration Geophysicists, 2-7 November 1997, Dallas, USA, Conf. paper SEG-1997-1151, 1151-1154.

Barnes, A.E. (2000), Attributes for automating seismic facies analysis. In: Proc. 70th Annual Meeting, Society of Exploration Geophysicists, 6-11 August 2000, Calgary, Canada, Conf. paper SEG-2000-0553, 553-556.

Bell, A.J., and T.J. Sejnowski (1997), The "independent components" of natural scenes are edge filters, Vision Res. 37, 23, 3327-3338, DOI: 10.1016/ S0042-6989(97)00121-1.

Birch, F. (1960), The velocity of compressional waves in rocks to 10 kbars - Part 1, J. Geophys. Res. 65, 4, 1083-1102, DOI: 10.1029/JZ065i004p01083.

Brocher, T.M. (2005), Empirical relations between elastic wavespeeds and density in the earth's crust, Bull. Seismol. Soc. Am. 95, 6, 2081-2092, DOI: $10.1785 / 0120050077$.

Brocher, T.M. (2008), Key elements of regional seismic velocity models for long period ground motion simulations, J. Seismol. 12, 2, 217-221, DOI: 10.1007/s10950-007-9061-3.

Brown, A.R. (1996), Seismic attributes and their classification, The Leading Edge 15, 10, 1090-1090, DOI: 10.1190/1.1437208.

Brown, A.R. (2004), Interpretation of Three-Dimensional Seismic Data, 6th ed., AAPG Memoir 42, American Association of Petroleum Geologists, Tulsa.

Burlini, L., and D.M. Fountain (1993), Seismic anisotropy of metapelites from the Ivrea-Verbano zone and Serie dei Laghi (northern Italy), Phys. Earth Planet. In. 78, 3-4, 301-317, DOI: 10.1016/0031-9201(93)90162-3. 
Carroll, R.D. (1969), The determination of the acoustic parameters of volcanic rocks from compressional velocity measurements, Int. J. Rock Mech. Min. 6, 6, 557-579, DOI: 10.1016/0148-9062(69)90022-9.

Castagna, J.P., M.L. Batzle, and T.K. Kan (1993), Rock physics - The link between rock properties and avo response. In: J.P. Castagna and M.M. Backus (eds.), Offset-Dependent Reflectivity - Theory and Practice of AVO Analysis, Society of Exploration Geophysicists, 135-171.

Chao, W., Ch. Mian, and J. Yan (2009), A prediction method of borehole stability based on seismic attribute technology, J. Petrol. Sci. Eng. 65, 3-4, 208-216, DOI: 10.1016/j.petrol.2008.12.033.

Chen, Q., and S. Sidney (1997), Seismic attribute technology for reservoir forecasting and monitoring, The Leading Edge 16, 5, 445-448, DOI: 10.1190/ 1.1437657 .

Christensen, N.I. (1974), Compressional wave velocities in possible mantle rocks to pressures of 30 kilobars, J. Geophys. Res. 79, 2, 407-412, DOI: 10.1029/ JB079i002p00407.

Comon, P. (1994), Independent component analysis, a new concept? Signal Process. 36, 3, 287-314, DOI: 10.1016/0165-1684(94)90029-9.

Cosentino, L. (2001), Integrated Reservoir Studies, Editions Technip, Paris.

Eberhart-Phillips, D., D.-H. Han, and M.D. Zoback (1989), Empirical relationships among seismic velocity, effective pressure, porosity, and clay content in sandstone, Geophysics 54, 1, 82-89, DOI: 10.1190/1.1442580.

Gassmann, F. (1951), Elasticity of porous media, Vierteljahrsschrift der Naturforschenden Gesellschaft in Zürich 96, 1, 1-23 (in German).

Greenberg, M.L., and J.P. Castagna (1992), Shear-wave velocity estimation in porous rocks: theoretical formulation, preliminary verification and applications, Geophys. Prospect. 40, 2, 195-209, DOI: 10.1111/j.1365-2478. 1992.tb00371.x.

Hampson, D.P., J.S. Schuelke, and J.A. Quirein (2001), Use of multiattribute transforms to predict log properties from seismic data, Geophysics 66, 1, 220236, DOI: $10.1190 / 1.1444899$.

Hart, B.S., and R.S. Balch (2000), Approaches to defining reservoir physical properties from 3-D seismic attributes with limited well control: An example from the Jurassic Smackover Formation, Alabama, Geophysics 65, 2, 368-376, DOI: $10.1190 / 1.1444732$.

Hyvärinen, A. (1999a), Survey on independent component analysis, Neural. Comput. Surv. 2, 94-128.

Hyvärinen, A. (1999b), Fast and robust fixed-point algorithms for independent component analysis, IEEE Trans. Neural Networks. 10, 3, 626-634, DOI: $10.1109 / 72.761722$. 
Hyvärinen, A., and E. Oja (2000), Independent component analysis: algorithms and applications, Neural Networks 13, 4-5, 411-430, DOI: 10.1016/S08936080(00)00026-5.

Ji, S.C., and M.H. Salisbury (1993), Shear-wave velocities, anisotropy and splitting in high-grade mylonites, Tectonophysics 221, 3-4, 453-473, DOI: 10.1016/ 0040-1951(93)90173-H.

Ji, S.C., Q. Wang, and B. Xia (2002), Handbook of Seismic Properties of Minerals, Rocks and Ores, Polytechnic International Press, Montreal, 630 pp.

Kalkomey, C.T. (1997), Potential risks when using seismic attributes as predictors of reservoir properties, The Leading Edge 16, 3, 247-251, DOI: 10.1190/ 1.1437610 .

Kern, H. (1982), P- and S-wave velocities in crustal and mantle rocks under the simultaneous action of high confining pressure and high temperature and the effect of the rock microstructure. In: W. Schreyer (ed.), High-Pressure Researches in Geoscience, E. Schweizerbart'sche Verlagsbuchhandlung, Stuttgart, 15-45.

Khademi, J., K. Shahriar, B. Rezai, and J. Rostami (2010), Performance prediction of hard rock TBM using Rock Mass Rating (RMR) system, Tunn. Undergr. Sp. Tech. 25, 4, 333-345, DOI: 10.1016/j.tust.2010.01.008.

Krief, M., J. Garat, J. Stellingwerff, and J. Ventre (1990), A petrophysical interpretation using the velocities of $\mathrm{P}$ and $\mathrm{S}$ waves (full-waveform sonic), The Log Analyst 31, 8, 355-369.

Lee, T.-W. (1998), Independent Component Analysis. Theory and Applications, Springer, Dordrecht, DOI: 10.1007/978-1-4757-2851-4.

Liner, C., C.-F. Li, A. Gersztenkorn, and J. Smythe (2004), SPICE: A new general seismic attribute. In: Proc. 72nd Annual International Meeting, Society of Exploration Geophysicists, 10-15 October 2004, Denver, USA, Conf. paper SEG-2004-0433, 433-436.

Masters, T. (1993), Practical Neural Network Recipes in $C++$, Academic Press, San Diego.

McCormack, M.D. (1990), Seismic trace editing and first break picking using neural networks. In: Proc. 60th Annual International Meeting, Society of Exploration Geophysicists, 23-27 September 1990, San Francisco, USA, Conf. paper SEG-1990-0321, 321-324.

McCulloch, W.S., and W. Pitts (1943), A logical calculus of the ideas immanent in nervous activity, Bull. Math. Biophys. 5, 4, 115-133, DOI: 10.1007/ BF02478259.

Meldahl, P., R. Heggland, B. Bril, and P. de Groot (2001), Identifying faults and gas chimneys using multiattributes and neural networks, The Leading Edge 20, 5, 474-482, DOI: 10.1190/1.1438976. 
Neves, F.A., M.S. Zahrani, and S.W. Bremkamp (2004), Detection of potential fractures and small faults using seismic attributes, The Leading Edge 23, 9, 903-906, DOI: 10.1190/1.1803500.

Pickett, G.R. (1963), Acoustic character logs and their applications in formation evaluation, J. Petrol. Technol. 15, 6, 659-667, DOI: 10.2118/452-PA.

Poulton, M.M. (2002), Neural networks as an intelligence amplification tool: A review of applications, Geophysics 67, 3, 979-993, DOI: 10.1190/1.1484539.

Rezaee, M.R., and J.K. Applegate (1997), Shear velocity prediction from wireline logs, an example from Carnarvon Basin, NW shelf, Australia. In: Proc. 67th Annual Meeting, Society of Exploration Geophysicists, 2-7 November 1997, Dallas, USA, Conf. paper SEG-1997-0945, 945-947.

Rosenblatt, F. (1958), The perceptron: A probabilistic model for information storage and organization in the brain, Psychol. Rev. 65, 6, 386-408, DOI: $10.1037 /$ h0042519.

Russell, B.H., L.R. Lines, and D.P. Hampson (2003), Application of the radial basis function neural network to the prediction of log properties from seismic attributes, Explor. Geophys. 34, 1/2, 15-23, DOI: 10.1071/EG03015.

Schmitt, D.R. (1999), Seismic attributes for monitoring of a shallow heated heavy oil reservoir: A case study, Geophysics 64, 2, 368-377, DOI: 10.1190/ 1.1444541 .

Sheline, H. (2005), Don't abuse seismic attributes, AAPG Explorer 26, 1, 22-23.

Sheriff, R.E (2002), Encyclopedic Dictionary of Applied Geophysics, 4th ed., Geophysical References Series, Vol. 13, Society of Exploration Geophysicists, Tulsa, USA.

Singh, R., A. Kainthola, and T.N. Singh (2012), Estimation of elastic constant of rocks using an ANFIS approach, Appl. Soft. Comput. 12, 1, 40-45, DOI: 10.1016/j.asoc.2011.09.010.

Taner, M.T., J.S. Schuelke, R. O’Doherty, and E. Baysal (1994), Seismic attributes revisited, SEG Technical Program, Expanded Abstracts 1994, 1104-1106, DOI: $10.1190 / 1.1822709$.

Todoeschuck, J.P., and O.G. Jensen (1988), Joseph geology and seismic deconvolution, Geophysics 53, 11, 1410-1414, DOI: 10.1190/1.1442420.

Turcotte, D.L. (1989), Fractals in geology and geophysics, Pure Appl. Geophys. 131, 1/2, 171-196, DOI: 10.1007/978-3-0348-6389-6_10.

Uden, R.C., M. Smith, and L. Hübert (2003), Neural network training for reservoir characterization of litho facies. In: Proc. EAGE 65th Conference \& Exhibition, 2-5 June 2003, Stavanger, Norway, Z-99.

Upham, W., and P. Cary (1991), Comparison of linear and nonlinear neural networks for seismic trace editing. In: Proc. 61st Annual Meeting, Society of Exploration Geophysicists, 10-14 November 1991, Houston, USA, Conf. paper SEG-1991-0293, 293-294. 
van der Baan, M., and C. Jutten (2000), Neural networks in geophysical applications, Geophysics 65, 4, 1032-1047, DOI: 10.1190/1.1444797.

Walden, A.T., and J.W.J. Hosken (1985), An investigation of the spectral properties of primary reflection coefficients, Geophys. Prospect. 33, 3, 400-435, DOI: 10.1111/j.1365-2478.1985.tb00443.x.

Walker, R., C. Wong, H. Malcotti, E. Pèrez, and J. Sierra (2005), Seismic multiattribute analysis for lithology discrimination in Ganso Field, Oficina Formation, Venezuela, The Leading Edge 24, 11, 1160-1166, DOI: 10.1190/ 1.2135131 .

Wantland, D. (1964), Geophysical measurements of rock properties in situ. In: W.R. Judd (ed), Proc. Int. Conf. "State of Stress in Earth's Crust", 13-14 June 1963, Santa Monica, USA, 409-450.

Watanabe, T., H. Kasami, and S. Ohshima (2007), Compressional and shear wave velocities of serpentinized peridotites up to $200 \mathrm{MPa}$, Earth Planets Space 59, 4, 233-244.

Yasar, E., and Y. Erdogan (2004), Correlating sound velocity with the density, compressive strength and Young's modulus of carbonate rocks, Int. J. Rock Mech. Min. Sci. 41, 5, 871-875, DOI: 10.1016/j.ijrmms.2004.01.012.

Zeng, J., Y. Shu, and Y. Zhong (1995), Fractal and chaotic characteristics of seismic data, Oil Geophys. Prospect. 30, 6, 743-748 (in Chinese).

Received 23 April 2013

Received in revised form 15 September 2013

Accepted 18 September 2013 